\title{
EfFect of Vehicles' Suspension on Highway Horizontal CURve Design
}

\author{
By Tang-Hsien Chang ${ }^{1}$
}

\author{
(Reviewed by the Highway Division)
}

\begin{abstract}
From the perspective of vehicles with a suspension system, some conventional highway design criteria do not adhere to vehicle characteristics. In particular, the relationship between minimum radius, superelevation, side friction, and design speed should be modified to incorporate modern vehicle design in body rolling. This study addresses the limitations of conventional design criteria for horizontal curves. A more appropriate equation is derived. From the revised equation, roughly $12-30 \%$ of the deflected fraction of the conventional minimum radius criteria was found. In order to ensure driving safety based on the values obtained from the revised equation, an evaluation of existing highway curves is proposed. This study also suggests that highway agencies should improve unsatisfactory sections and install speed calming measures at places that cannot be modified.
\end{abstract}

\section{INTRODUCTION}

While vehicle engineers are responsible for designing safe and comfortable vehicles, highway engineers are responsible for providing safe highways. The consumer-oriented nature of vehicle markets accounts for why vehicle design is continuing to improve for purchasers and occupants. However, highway design is still not compatible with modern vehicle design. From the perspective of modern vehicles, a further design criterion for highways must be proposed. This study analyzes the conventional highway horizontal design criteria from the perspective that the applied relationship of minimum radius, superelevation, side friction, and design speed cannot aptly describe and adapt to modern vehicle design suspensions. Based on that criteria, current radius provisions cannot fulfill actual requirements. Most drivers on such curves have to decelerate to reduce their original speeds. According to Nicholson (1998), highway design attempts to achieve a consistent alignment design, thereby allowing most drivers to safely operate at their desired speed along the entire section of the road. Achieving alignment consistency hinges not only on considering highway infrastructure, but also on incorporating vehicle design. Under this situation, conventional criteria must be carefully reviewed. Horizontal design standards set lateral accelerations based on the level of comfort experienced by drivers during experiments completed prior to 1940 (Moyer and Berry 1940). Drivers frequently drive faster than the advised speeds for horizontal curves that are based on early notions of comfort (Badeau and Bass 1995). Felipe and Navin (1999) indicated that driving speeds and vehicle tracks do not sufficiently match the provided radii on the basis of AASHTO criteria. According to their results, conventional criteria do not properly combine the highway layout with modern vehicle and driver behavior and, therefore, do not provide adequate safety for road users.

This study assesses the conventional approach of geometric design in horizontal alignment (i.e., considering unsprung vehicles) as well as a more reasonable approach to describe a vehicle with a suspension system when traveling around a curve. When such a vehicle is traveling around a curve, a

${ }^{1}$ Prof., Dept. of Civ. Engrg., Nat. Taiwan Univ., P.O. Box 7-876, Taipei, Taiwan 10617. E-mail: thchang@ce.ntu.edu.tw

Note. Discussion open until July 1, 2001. To extend the closing date one month, a written request must be filed with the ASCE Manager of Journals. The manuscript for this technical note was submitted for review and possible publication on January 22, 1999. This technical note is part of the Journal of Transportation Engineering, Vol. 127, No. 1, January/ February, 2001. CASCE, ISSN 0733-947X/01/0001-0089-0091/\$8.00 + $\$ .50$ per page. Technical Note No. 20105. portion of its weight shifts to the outside due to body roll and causes unbalanced loading between the inside and outside tires. This situation alters the conventional relationship between minimum radius, superelevation, side friction, and design speed. The relevant equation derived herein indicates the inability of conventional highway design to adhere to the vehicle dynamics.

\section{RIGID VEHICLE VERSUS SPRUNG VEHICLE}

When considering the horizontal alignment of a highway, all geometric elements should be designed to ensure vehicle safety and stability as well as comfort of occupants. Curve design must establish curvature and superelevation, based on a given design speed and side friction. The conventional design criteria are built on a rigid, unsprung vehicle, as depicted in Fig. 1. On considering the horizontal skidding factor, taking the balance of the lateral forces and assuming that the crossslope is quite small, i.e., $f \sin \theta \ll 0$, this yields

$$
R=\frac{\mathrm{v}^{2}}{g(e+f)}=\frac{V^{2}}{127(e+f)}
$$

where $R$ denotes curve radius in meters; $v$ represents vehicular speed $(\mathrm{m} / \mathrm{s})$ in cornering; $V=$ speed in kilometers per hour $(\mathrm{kph}) ; g=$ acceleration of gravity; $f$ and $\theta$ represent lateral friction coefficient and pavement cross-slope angle, respectively; and $e=\tan \theta \approx \theta$. Eq. (1) is the conventional AASHTO design basis for superelevation and minimum radius requirement at a certain design speed. For such a superelevated provision, taking moments about the point where the outside tire contacts the ground leads to

$$
F_{\mathrm{zi}} t+\left(W \mathrm{~V}^{2} / g R\right) \cdot h-W \cdot t / 2-W \theta \cdot h=0
$$

where $W$ denotes the vehicle weight in Newtons; $F_{\mathrm{zi}}$ is defined as the reaction force from the ground acting at the inside wheels of a vehicle while turning; $F_{\text {zo }}$ denotes the reaction force at the outside wheel; $h$ denotes the height of mass center CG over the ground (in meters); and $t$ is the tread (in meters) representing the average width between the centers of the lefthand and the right-hand wheels of a vehicle. Since $e=\tan \theta$ $\approx \theta$, then

$$
e+\left(t / 2 h-F_{\mathrm{zi}} t / W h\right)=\frac{\mathrm{v}^{2}}{g R}
$$

By incorporating (1) and (3), the friction coefficient is approximately 


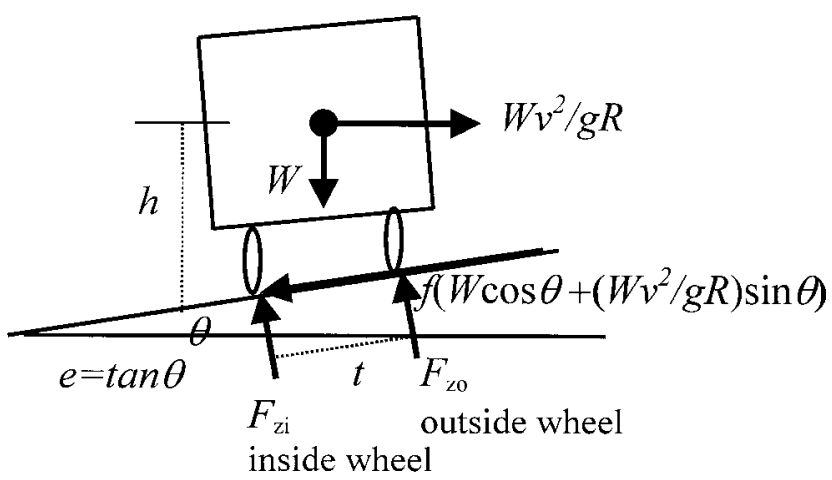

FIG. 1. Free-Body of Unsprung Vehicle

$$
f=\left(t / 2 h-F_{\mathrm{zi}} t / W h\right)
$$

When a vehicle is traveling around a curve, the limiting condition occurs when the load on the inside wheels reaches zero and lifts off the ground. Thus, the rollover threshold is given by

$$
\frac{\mathrm{v}^{2}}{g R}=e+t / 2 h
$$

Unlike Fig. 1, Fig. 2 illustrates the condition of a vehicle equipped with a suspension system. In the dynamic behavior, such a sprung vehicle can be separated into two major portions: the upper car body and the lower chasis body. When such a vehicle is traveling around a curve, the upper body will have a relative roll with respect to the lower body at a makeup roll center, $O$. Meanwhile, the lateral load transfer unloads the inside wheels of the vehicle and increases the load on the outside wheels. Thus, the reaction force $F_{\mathrm{zi}}$ of the inside wheels on the ground surface is different from that $F_{\mathrm{zo}}$ of the outer wheels. The outcome is a body roll with a lateral shift of the center of gravity toward the outside of the turn. The offset of the center of gravity reduces the moment arm, on which the gravity force acts to resist the rollover. In Fig. 2, the roll center at $O$ offsetting $h_{o}$ from the ground is the pivot around which the upper vehicle body roll occurs; $\phi$ is the roll angle. Taking moments about the point where the outside tire comes into contact with the ground yields

$$
F_{\mathrm{zi}} t+\frac{W \mathrm{v}^{2}}{g R} h-W\left[\frac{t}{2}-\left(h-h_{o}\right)(\phi-\theta)\right]=0
$$

Thus, the rollover threshold of a vehicle with a suspension system is at



FIG. 2. Free-Body of Sprung Vehicle

$$
\frac{\mathrm{v}^{2}}{g R}=\left[\left(1-\frac{h_{o}}{h}\right)(e-\phi)\right]+t / 2 h
$$

Eq. (7) is equivalent to (5) when both $h_{o}$ and $\phi$ of an unsprung vehicle vanish. In general, $0 \leq h_{o} \leq h$ and $\phi \geq 0$ at a turn. The rollover threshold of a sprung vehicle is, evidently, smaller than that of an unsprung vehicle, since the first term of the right-hand side in (7) is smaller than $e$; even the first term becomes negative while $\phi>e$. Thus, neglecting the effect of tires and suspensions overestimates the rollover threshold of a vehicle (Bernard et al. 1989). The phenomenon of vehicles with suspension systems is a fact, indicating that highway engineers should pay closer attention to such oversightedness in conventional highway design, particularly in horizontal curve design, in which the criteria are still based on an unsprung vehicle's structure. Applying (1) is obviously optimistic of highway engineers. A more reasonable equation considering suspension instead of (1) is derived hereafter. Now the roll angle of the sprung vehicle, $\phi$, is simply the roll rate of sprung mass, $r_{\phi}$, times the lateral acceleration, $a_{y}$. This can be expressed as follows:

$$
\phi \approx r_{\phi} \cdot a_{y}=r_{\phi} \cdot \frac{\mathrm{v}^{2}}{g R}
$$

Substituting (8) into (6) and incorporating (4), will approximately lead to

$$
R=\frac{\mathrm{v}^{2}}{g\left[\left(1-\frac{h_{o}}{h}\right) e+f\right]}\left[1+r_{\phi}\left(1-\frac{h_{o}}{h}\right)\right]
$$

where $\theta$ is replaced by $e$ denoted in radians. Compared with (1), (9) has additional variables, including the roll rate and the height ratio of the rolling center to the center of gravity (CG). Eq. (9) reveals that the larger the roll rate in vehicles, the longer the curve radius is needed. However, the larger height ratio reduces the effect since $r_{\phi}$ is much greater than $e$, thereby affecting the denominator. Restated, the closer the rolling center to CG implies a greater tendency of the roll rate to approach zero.

\section{REVISION OF HORIZONTAL DESIGN CRITERIA}

According to (9), conventional horizontal design can be improved in two aspects. One way is to provide an increase of the superelevation based on (9) under conventional design speed and existing radius, while the other is to extend the minimum radius. However, the major function of superelevation is to overcome the lateral force of vehicles sliding away from the center of a lane. Indeed, from (9), superelevation's contribution to rollover is relative little, since $r_{\phi}$ is generally greater than $e$. And the maximum superelevation recommended by AASHTO $(1984,1990)$ is set to 0.12. Therefore, the method of extending radii to prevent rollover is much more effective than that of increasing the superelevation.

The previous section has verified that (9) is more feasible for modern practice than (1). According to Fundamentals of Vehicle Dynamics (Gillespie 1992), for a typical passenger car the height ratio $h_{o} / h \approx 0.5$ (e.g., independent suspensions) and the roll rate $r_{\phi} \approx 0.1$ radians $/$ g. For a truck, $h_{o} / h \approx 0.25$ (e.g., solid axes) and $r_{\phi} \approx 0.05$ radians/g. Substituting the parameters, height ratio, and roll rate of these two types of vehicles into (9) yields

$$
\begin{gathered}
R_{i}=\frac{V^{2}}{121(0.5 e+f)} \text { for passenger cars } \\
R_{i}=\frac{V^{2}}{122.5(0.75 e+f)} \text { for trucks }
\end{gathered}
$$


where $R_{i}$ denotes the ideal minimum radius considering sprung vehicles. From the perspective of vehicular design, trucks normally have a harder stiffness of suspension than passenger cars. Therefore, if a truck is loaded within a confined/legal range, without exceeding its height ratio, the truck should appear more stable in body rolling than a passenger car. Comparing (10) with (11) reveals that for the case of a passenger car, it is obviously more critical than that for a truck in this respect. Thus, a common passenger car's parameters are utilized herein for improving the horizontal design criteria.

Assuming that design speed $V$ ranges from 30 to $120 \mathrm{kph}$, superelevation $e$ of the order of $0.04,0.06,0.08,0.10$, and 0.12 , and side-friction coefficient $f$ within $0.10-0.17$, respectively, and by examining (1) and (9), the resulting radii obtained from (9) are always larger than those from (1). Based on the calculation of $[(1)-(9)] /(9)$, the deflected fractions of current AASHTO criteria for minimum radii are observed to be about $12-30 \%$, compared to the actual requirements presented by (9). The examination demonstrates that the fraction becomes larger with an increasing superelevation. The result also indicates that the factor of the rollover threshold [(9)] overwhelms the factor of horizontal skidding [(1)] in determining the minimum radius. Thus, closely examining current design criteria reveals that replacing (1) by (9) is a means of introducing modern vehicle design to the highway horizontal curve design. More attention should be given to this to include the effect of sprung vehicles.

\section{CONCLUSIONS AND SUGGESTIONS}

Consistency between highway design and vehicle design is highly desirable when attempting to minimize the frequencies of series accidents and violations of driver expectancy upon encountering curves. AASHTO's minimum radius design criteria is based on the concept of antiskidding from horizontal phases. However, this study proves that, for modern vehicles' design, the effect of the rolling factor exceeds that of the hor- izontal skidding on a highway horizontal curve. This means that, in essence, to derive the speed-radius-superelevation relationship for curve design, the application of the rolling approach is more reasonable than applying the balancing lateral force approach. The key safety factor of modern vehicles on a curve is rolling rather than lateral skidding. In the past, most accidents on curves were rollovers.

This study has presented a more appropriate equation capable of aptly describing the relation between minimum radius, superelevation, side friction, and design speed. The approach proposed herein can provide a valuable reference for modifying conventional highway design criteria. For existing roads, this study recommends an evaluation of current highways and an improvement of unsatisfactory curves. For safety concerns, speed-calming measures should be installed at those curved sections that are difficult to reconstruct. Results from this study also demonstrate that the deflected fraction becomes larger with an increasing superelevation, implying that highway engineers should pay closer attention to high superelevation curves.

\section{APPENDIX. REFERENCES}

AASHTO. (1984, 1990). A policy on geometric design of highways and streets, American Association of State Highway and Transportation Officials, Washington, D.C.

Badeau, N., and Bass, K. G. (1995). "Safe speed determination in curves." Proc., Can. Multidisciplinary Road Safety Conf. IX, Montreal, 457-467.

Bernard, J., Shannan, J., and Vanderploeg, V. (1989). "Vehicle rollover on smooth surfaces." SAE Paper 891991, SAE Inc., Warrendale, Pa.

Felipe, E., and Navin, F. (1999). "Automobiles on horizontal curves, experiments and observations." Transportation research record, TRB, $1628,50-56$.

Gillespie, T. D. (1992). Fundamentals of vehicle dynamics, SAE Inc., Warrendale, $\mathrm{Pa}$.

Moyer, R. A., and Berry, D. S. (1940). "Marking highway curves with safe speed indicators." HRB Proc., 20, 399-428.

Nicholson, A. (1998). "Superelevation, side friction, and roadway consistency." J. Transp. Engrg., ASCE, 124(5), 411-418. 